\title{
THE USE OF $\alpha$-BENZOINOXIME IN THE DETERMINATION OF MOLYBDENUM
}

\author{
By H. B. Knowles
}

ABSTRACT

Present methods for the determination of molybdenum in any considerable amount require a number of tedious and time-consuming operations prior to the actual determination of that element. $\alpha$-benzoinoxime, advocated as being specific for copper, has been found to precipitate molybdenum quantitatively and to isolate it from most of the more commonly encountered elements. As a result of the present study a procedure has been developed by which molybdenum can be determined in ores, steels, and other products in much less time than by present methods and with all the accuracy of the best methods now in use.

I. Introduction

II. Experimental

1. Preliminary considerations

(a) Permissible acidity

(b) Temperature of the solution

(c) Amount of reagent required

(d) Time necessary for complete precipitation

(e) Washing the precipitate.....

$(f)$ Final treatment of the precipitate

2. Procedure recommended for general use

3. Behavior of other elements in recommended procedure....

4. Applications of the procedure

(a) Analysis of steel

(b) Analysis of ores and commercial products

III. Acknowledgments

\section{INTRODUCTION}

In an investigation of some reagents proposed as being specifics for copper, consideration was given $\alpha$-benzoinoxime, which has been recommended by Feigl, ${ }^{1}$ and for which he has proposed the name "Cupron." Briefly, it is stated by Feigl that complete precipitation of copper results when an alcoholic solution of the reagent is added to a hot, "clear blue" ammoniacal solution of copper. In the presence of iron, aluminum, lead, etc., precipitation is made in an ammoniacal tartrate solution, while in the presence of nickel, a tartaric acid solution buffered with tartrate is recommended. The resulting precipitate is said to be insoluble in water, alcohol, dilute ammonium hydroxide, acetic, and tartaric acids; easily soluble in mineral acids and slightly soluble in concentrated ammonium hydroxide. After appropriate washing it is dried and weighed as

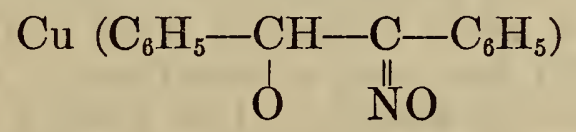

containing 22.02 per cent of copper.

1 F. Feigl, Ber., vol. 56, II, p. 2083, 1923. 
The desirability of using $\alpha$-benzoinoxime for the precipitation of copper in the presence of other elements, notably molybdenum, led to a study of the behavior of the reagent toward such elements. Preliminary tests disclosed the fact that while the reagent was not as specific for copper as could be wished, it did present interesting possibilities in its reactions with molybdenum. This element was not only quantitatively precipitated in an acetic acid solution buffered with acetate, but also in cold mineral acid solutions containing as much as 20 per cent by volume of sulphuric acid.

\section{EXPERIMENTAL}

\section{PRELIMINARY CONSIDERATIONS}

(a) PERMISSIBLE ACIDITY

Experiments showed that to prevent the interference of certain elements the solution must be distinctly acid with either sulphuric, hydrochloric, or nitric acid. A solution containing 5 per cent by volume of sulphuric acid is preferable, although good precipitations were also obtained from solutions containing as much as 20 per cent by volume of sulphuric acid. Solutions containing 5 per cent of hydrochloric or nitric acid gave excellent results in instances, in which sulphuric acid was objectionable, such as in the presence of tin or lead. Successful precipitations were also obtained in solutions containing 5 per cent by volume of phosphoric acid. Precipitations made in the presence of tartaric acid were not quite complete, while those made in solutions containing hydrofluoric acid indicated that this acid must be absent.

\section{(b) TEMPERATURE OF THE SOLUTION}

Precipitations at $80^{\circ}$ to $90^{\circ} \mathrm{C}$., as well as those performed at room temperature showed that there was danger of reducing sexivalent molybedenum before it was precipitated. Experiments showed that this condition was avoided best by working with a cold solution and adding sufficient bromine water to faintly tinge the solution after the addition of the reagent.

\section{(c) AMOUNT OF REAGENT REQUIRED}

When slightly more than the theoretical quantity of the reagent was used, as determined by the relation 1 Mo to $3 \mathrm{C}_{6} \mathrm{H}_{5} \cdot \mathrm{CH}(\mathrm{OH})$. $\mathrm{C}:(\mathrm{NOH}) \cdot \mathrm{C}_{6} \mathrm{H}_{5}$, incomplete precipitation resulted. Similar unsatisfactory results prevailed when ten times the theoretical quantity of reagent was employed. This effect may have been caused, in part, by the large quantity of alcohol added with the reagent. It was found that from two to five times the theoretical amount of reagent provided an adequate excess.

\section{(d) TIME NECESSARY FOR COMPLETE PRECIPITATION}

Experiments to determine the time necessary for complete precipitation showed that although filtration could be begun almost immediately following the final addition of the reagent, equally satisfactory results were obtained when filtrations were made at the end of 10 minutes, during which time ample opportunity was afforded to permit intermittent thorough stirring. Low results were obtained when the precipitates were allowed to remain in contact with the solutions for 30 minutes. 
(e) WASHING THE PRECIPITATE

It was found that water, absolute ethyl alcohol, and various mixtures of diluted alcohol containing a little sulphuric acid were not suitable for washing the precipitate. The most promising wash solution was found to be a cold, diluted sulphuric acid (1 per cent by volume) containing a small amount of $\alpha$-benzoinoxime.

(f) FINAL TREATMENT OF THE PRECIPITATE

Experiments in which it was sought to weigh or titrate the molybdenum precipitate, after appropriate washing and drying, gave no immediate indication of success, and further attempts were abandoned. Difficulties, such as are experienced in the direct ignition of some organic compounds, were not encountered, for it was found that the precipitate could be ignited directly to molybdic oxide after a short drying.

\section{PROCEDURE RECOMMENDED FOR GENERAL USE}

Prepare a solution containing $10 \mathrm{ml}$ of sulphuric acid (specific gravity 1.84) in a volume of $200 \mathrm{ml}$ and not more than $0.15 \mathrm{~g}$ of sexivalent molybdenum. If vanadates or chromates are present add sufficient freshly prepared sulphurous acid to reduce them and heat to boiling. Continue the boiling until the odor of sulphur dioxide can no longer be detected. Chill the solution to a temperature of $5^{\circ}$ to $10^{\circ} \mathrm{C}$. Stir and slowly add $10 \mathrm{ml}$ of a solution of $2 \mathrm{~g}$ of $\alpha$-benzoinoxime in $100 \mathrm{ml}$ of alcohol and $5 \mathrm{ml}$ extra for each $0.01 \mathrm{~g}$ of molybdenum present. Continue to stir the solution, add just sufficient bromine water to tint the solution a pale yellow and then add a few milliliters of the reagent. Allow the beaker and contents to remain in the cooling mixture 10 to 15 minutes with occasional stirring, stir in a little macerated filter pulp and filter through a paper of close texture, such as S. \& S. No. 589 Blue Band. Filtration can be greatly facilitated by using a coarser filter, such as S. \& S. No. 589 Black Band, but it is then requisite that the filtrate be very carefully examined and the first portions refiltered if they are not absolutely clear. Wash the precipitate with $200 \mathrm{ml}$ of a cold, freshly prepared solution containing 25 to $50 \mathrm{ml}$ of the prepared reagent and $10 \mathrm{ml}$ of sulphuric acid in $1,000 \mathrm{ml}$. On standing, the filtrate will deposit needlelike crystals if sufficient reagent has been employed.

Transfer the washed precipitate to a weighed platinum crucible, cautiously dry; char, without flaming, over a very low gas flame and then ignite to constant weight in an electric muffe at $500^{\circ}$ to $525^{\circ} \mathrm{C}$. In umpire analyses of materials containing silica it is best to remove that constituent before proceeding with the precipitation of molybdenum rather than to treat the final precipitate with sulphuric and hydrofluoric acids, because of the uncertainty of completely decomposing molybdenum sulphate at the temperature of ignition. If the oxide contains no impurities, except tungsten, it should dissolve completely in warm dilute ammonium hydroxide. If an insoluble residue remains, it must be separated by filtration, ignited, weighed, and the weight subtracted. If tungsten may be present, the clear ammoniacal solution should be acidified with hydrochloric acid and treated with cinchonine as in II, $4(b)$, " analysis of ores and commercial products." 
Results obtained by use of the recommended procedure with pure solutions of molybdenum are given in Table 1.

TABLE 1.-Determination of molybdenum in pure solution

\begin{tabular}{|c|c|c|c|}
\hline $\begin{array}{l}\text { Experiment } \\
\text { No. }\end{array}$ & Mo added & Mo found & Differenco \\
\hline & 0.0001 & 0.0001 & 0.0000 \\
\hline & .0010 & .0009 & -.0001 \\
\hline & .0051 & .0051 & .0000 \\
\hline $4-$. & $\begin{array}{r}.0103 \\
0205\end{array}$ & .0101 & -.0002 \\
\hline $6-$ & .0513 & .0513 & .0000 \\
\hline 7. & .1026 & .1027 & +.0001 \\
\hline
\end{tabular}

\section{BEHAVIOR OF OTHER ELEMENTS IN RECOMMENDED PROCEDURE}

In a survey of the behavior of other elements in the procedure recommended in II, 2, the following elements were studied: Silver, lead, mercury, bismuth, copper, cadmium, arsenic, antimony, tin, selenium, tellurium, aluminum, iron, titanium, zirconium, chromium, vanadium, silicon, tungsten, tantalum, columbium, cerium, uranium, rhenium, nickel, cobalt, manganese, zinc, and the members of the platinum group-ruthenium, rhodium, palladium, osmium, iridium, and platinum.

The only elements that give precipitates in mineral acid solutions with $\alpha$-benzoinoxime are tungsten, palladium, sexivalent chromium, quinquevalent vanadium, and tantalum. The precipitation of tungsten and palladium is seemingly quantitative and the use of $\alpha$-benzoinoxime in quantitative determinations of these elements is being studied. For example, in a determination of molybenum in the Bureau of Standards standard sample of chrome-vanadium steel No. 72 the result obtained was too high. The error was afterwards found to be caused by tungsten, the presence of which had not been previously noted. The precipitation of sexivalent chromium and quinquevalent vanadium was not studied because satisfactory methods for their determination are available, and it was found that they cause no interference when reduced to lower valences $\left(\mathrm{Cr}^{\mathrm{III}}\right.$ and $\left.\mathrm{V}^{\mathrm{IV}}\right)$. The precipitate with tantalum appeared more like the hydrated acid than a compound with the reagent, and the reaction was not studied further because tantalum occurs but seldom, and most of it would be removed before precipitation of molybdenum would be attempted.

Silver, lead, mercury, bismuth, copper, cadmium, arsenic, antimony, tin, aluminum, iron, titanium, zirconium, trivalent chromium, quadrivalent vanadium, cerium, uranium, nickel, cobalt, manganese, and zinc are not precipitated either when alone or when associated with molybdenum. Experiments dealing with mixtures of these elements are shown in Table 2. The separation of molybdenum from antimony is of particular interest because good methods for the separation of these elements are lacking.

Selenium, tellurium, rhenium, ruthenium, rhodium, osmium, iridium, and platinum are not precipitated when they occur alone. Their behavior when associated with molybdenum was not studied.

Columbium and silicon, in addition to the already mentioned sexivalent chromium, quinquevalent vanadium, palladium, tungsten, 
and tantalum contaminate the precipitate and must be removed before precipitation of molybdenum is attempted, or else determined in the weighed precipitate and deducted.

The results given in Table 2 were obtained when a single precipitation of molybdenum was made in the presence of other elements. With the exception of experiment No. 3, tests of the final precipitates showed no evidence of the presence of contaminating elements. The filtrate and washings from each experiment, after evaporation with nitric and sulphuric acids to destroy organic matter and testing colorimetrically by treating with potassium thiocyanate and stannous chloride ${ }^{2}$ showed less than $0.1 \mathrm{mg}$ of molybdenum.

TABLE 2.-Determination of molybdenum in the presence of other elements

\begin{tabular}{|c|c|c|c|c|}
\hline $\begin{array}{l}\text { Experiment } \\
\text { No. }\end{array}$ & Mo added & Mo found & Difference & Remarks \\
\hline & & & & \\
\hline & $\begin{array}{r}0.0103 \\
.0103\end{array}$ & $\begin{array}{r}0.0101 \\
.0102\end{array}$ & $\begin{array}{r}-0.0002 \\
-.0001\end{array}$ & $\begin{array}{l}\text { Precipitated in } 5 \text { per cent } \mathrm{HCl}+1 \text { per cent } \mathrm{HNO}_{3} \text {. } \\
\text { Precipitated in } 5 \text { per cent } \mathrm{HCl} \text {. }\end{array}$ \\
\hline & .0513 & .0632 & +.0119 & Precipitated in presence of $0.05 \mathrm{~g} \mathrm{~V} \mathrm{~V}$. \\
\hline & .0513 & .0514 & +.0001 & Precipitated in presence of $0.05 \mathrm{~g}$ VI \\
\hline & .0513 & .0514 & $-F .0001$ & $\begin{array}{l}\text { Precipitated in presence of } 0.05 \mathrm{~g} \mathrm{Sn}^{\mathrm{r}} \text { in } 5 \text { per cent } \\
\mathrm{HCl} \text {. }\end{array}$ \\
\hline 6. & .0513 & .0514 & +.0001 & $\begin{array}{l}\text { Precipitated in presence of } 0.05 \mathrm{~g} \text { each of } \mathrm{Ni}, \mathrm{Co}, \mathrm{Mn} \text {, } \\
\mathrm{Cr}^{\mathrm{mI}}, \mathrm{Fe}^{\mathrm{mIr}} \mathrm{Zn}, \mathrm{Cu} \text {. }\end{array}$ \\
\hline 7. & .0513 & .0514 & +.0001 & Precipitated in presence of $0.05 \mathrm{~g}$ each of $\mathrm{Ti}, \mathrm{Zr}$, \\
\hline 8. & .0513 & .0510 & -.0003 & $\begin{array}{l}\text { Precipitated in presence of } 0.05 \mathrm{~g} \text { each of } \mathrm{Pb}, \mathrm{Sb}, \mathrm{As} \text {, } \\
\text { after removal of } \mathrm{Pb} \text { as sulphate. } \mathrm{PbSO}_{4} \text { not }\end{array}$ \\
\hline 9. & .0513 & .0516 & +.0003 & $\begin{array}{l}\text { examined for Mo. } \\
\text { Precipitated in presence of } 0.05 \mathrm{~g} \text { each of } \mathrm{Ag}, \mathrm{Bi}, \mathrm{Cd} \text {, }\end{array}$ \\
\hline 10 & .0513 & .0516 & +.0003 & $\begin{array}{l}\text { Hgir } \\
\text { Precipitated in presence of } 0.05 \mathrm{~g} \text { Sb r in } 5 \text { per cent } \\
\text { acid ( } 50 \text { per cent } \mathrm{H}_{2} \mathrm{SO}_{4}: 50 \text { per cent } \mathrm{HCl} \text { ). }\end{array}$ \\
\hline
\end{tabular}

It was found that if correct colorimetric determinations of molybdenum are to be obtained the complete absence of nitric acid and platinum must be assured. The removel of nitric acid is readily accomplished by heating to fuming with an excess of sulphuric acid, while the absence of platinum is best assured by conducting all necessary fusions and evaporations in either silica or porcelain laboratory ware.

\section{APPLICATION OF THE PROCEDURE}

\section{(a) ANALYSIS OF STEEL}

To study the applicability of the procedure to the determination of small amounts of molybdenum in steel, samples of the Bureau of Standards standard sample No. 72 and of No. 11d with small additions of molybdenum were used. One-gram samples of the steel were dissolved in $50 \mathrm{ml}$ of diluted sulphuric acid $(1+6)$ and the solution treated with a minimum amount of nitric acid (specific gravity 1.42 ) to decompose carbides and oxidize the molybdenum. The solutions were filtered, if not perfectly clear, diluted to $100 \mathrm{ml}$ with water, cooled, treated with sufficient ferrous ammonium sulphate to reduce vanadic and chromic acids, and then cooled to $5^{\circ}$ to $10^{\circ} \mathrm{C}$. Five to ten milliliters of the $\alpha$-benzoinoxime reagent was added, followed by the addition of bromine water and a few more milliliters of the reagent. After standing 10 to 15 minutes, the precipitates

${ }^{2}$ Lundell, Hoffiman, and Bright, Chemical Analysis of Iron and Steel, p. 323, John Wiley \& Sons, New York, 1931. 
were filtered, washed, and ignited as in the procedure already described. The ignited oxides were examined for any insoluble residue and tungsten they might have contained.

The results obtained by the above procedure are shown in Table 3 .

TABLE 3.-Determination of molybdenum in steel

\begin{tabular}{|c|c|c|c|c|c|}
\hline \multirow{2}{*}{$\begin{array}{l}\text { Experiment } \\
\text { No. }\end{array}$} & \multirow{2}{*}{ Material } & \multicolumn{2}{|c|}{$\begin{array}{l}\text { Percentage of mo- } \\
\text { lybdenum }\end{array}$} & \multirow{2}{*}{$\begin{array}{l}\text { Differ- } \\
\text { ence }\end{array}$} & \multirow{2}{*}{ Remarks } \\
\hline & & $\begin{array}{c}\text { Added or } \\
\text { present }\end{array}$ & Found & & \\
\hline & $\begin{array}{l}\text { Chrome molybdenum } \\
\text { steel No. } 72 \text {. }\end{array}$ & $\begin{array}{c}\text { Per cent } \\
0.149\end{array}$ & $\begin{array}{c}\text { Per cent } \\
0.166\end{array}$ & $\begin{array}{l}\text { Per cent } \\
+0.017\end{array}$ & Gravimetric determination. \\
\hline & B. O. H. steel No. l]d & $\begin{array}{l}.149 \\
.0051\end{array}$ & $\begin{array}{l}.160 \\
.0054\end{array}$ & $\begin{array}{l}+.011 \\
+.0003\end{array}$ & $\begin{array}{l}\text { Do. } \\
\text { Colorimetric determination after }\end{array}$ \\
\hline & 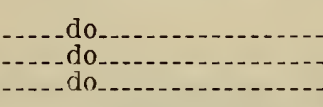 & $\begin{array}{l}.0103 \\
.51 \\
5.13\end{array}$ & $\begin{array}{l}.0096 \\
.52 \\
5.15\end{array}$ & $\begin{array}{l}-.0007 \\
+.01 \\
+.02\end{array}$ & $\begin{array}{l}\text { Solution of the precipitate. } \\
\text { Do. } \\
\text { Gravimetric determination. } \\
\text { Do. }\end{array}$ \\
\hline
\end{tabular}

(b) ANALYSIS OF ORES AND COMMERCIAL PRODUCTS

To study the applicability of the method to large amounts of molybdenum, determinations were made on the Bureau of Standards standard sample of calcium molybdate No. 71 and samples of wulfenite and molybdenite ore. The procedure adopted in the analysis of these materials consisted of an initial attack of 0.2 to $0.5 \mathrm{~g}$ of the material with either hydrochloric acid, nitric acid, or a mixture of both. Molybdenite is perhaps more readily attacked by treating with a mixture of fuming nitric acid (specific gravity 1.49) and bromine. Following the preliminary decomposition the solution was diluted with water, treated with $25 \mathrm{ml}$ of diluted sulphuric acid $(1+1)$ and evaporated until fumes of sulphuric acid appeared. After the addition of $100 \mathrm{ml}$ of water, the solution was heated to dissolve soluble sulphates, filtered, and washed with diluted sulphuric acid $(2+100)$. The insoluble residue obtained at this stage contained a small amount of molybdenum which was determined by fusing the residue with sodium carbonate, extracting with water, and making a colorimetric test of the water extract. The filtrate, at room temperature, was then diluted to $200 \mathrm{ml}$ and treated with a few drops of tenth normal potassium permanganate, enough to produce a permanent pink tinge, to insure complete oxidation of the molybdenum. Freshly prepared sulphurous acid was then added to reduce vanadates and chromates, and the solution boiled until no odor of sulphur dioxide could be detected. After thorough cooling, the solution was treated with an excess of $\alpha$-benzoinoxime, and the resulting precipitate filtered, washed, dried, ignited, and weighed. The ignited oxide was dissolved in the least possible amount of warm dilute ammonium hydroxide, filtered, washed with warm water, and the filter with its contents ignited and weighed. The ammoniacal extract containing all the molybdenum was acidified with hydrochloric acid, treated with cinchonine, digested overnight, and any precipitate of tungsten was filtered, washed, ignited at $525^{\circ} \mathrm{C}$. and weighed. The weight of this residue, together with that of the residue insoluble in ammonium hydroxide, was deducted from the weight of the molybdenum oxide. 
Results of the experiments are given in Table 4.

TABLE 4.-Determinations of molybdenum in ores and commercial products

\begin{tabular}{|c|c|c|c|}
\hline $\begin{array}{c}\text { Experiment } \\
\text { No. }\end{array}$ & Material & Mo found & Remarks \\
\hline & Calcium molybdate & $\begin{array}{l}\text { 35.22 per cent } \mathrm{Mo} \\
35.26 \text { per cent } \mathrm{Mo}\end{array}$ & \multirow{4}{*}{$\begin{array}{l}\text { Certificate value } 35.3 \text { per cent. } \\
11 \text { analysts reported values between } 18.29 \\
\text { and } 21.86 \text { per cent by various procedures. } \\
\text { Do. } \\
13 \text { andysts reported values between } 68.62 \\
\text { and } 74.79 \text { per cent by various procedures. } \\
\text { Do. }\end{array}$} \\
\hline & Wulfenite ore & 18.77 per cent $\mathrm{MoO}_{3}$ & \\
\hline & Molybdenite ore & $\begin{array}{l}\text { 18.84 percent } \mathrm{MoO}_{3} \\
70.4 \text { per cent } \mathrm{MoO}_{3}\end{array}$ & \\
\hline & 20. & 70.1 per cent $\mathrm{MoO}_{3}$ & \\
\hline
\end{tabular}

In some further tests on the wulfenite ore, a $5 \mathrm{~g}$ sample was treated as described, and the solution diluted to exactly $500 \mathrm{ml}$ after decomposition and the removal of the lead as sulphate. Direct precipitation with $\alpha$-benzoinoxime in $50 \mathrm{ml}$ aliquots indicated $18.73,18.67$, and 18.73 per cent of molybdenum trioxide. Tests on similar aliquots indicated 18.77 and 18.75 per cent after the long and tedious process of eliminating arsenic and vanadium by triple precipitation with ammonium hydroxide in the presence of ferric iron, separation from tungsten by precipitation of the molybdenum as sulphide from an acid solution containing tartaric acid, recovery of the molybdenum which escaped the sulphide precipitation and other time-consuming attendant operations. The removal of copper, which does not interfere in the $\alpha$-benzoinoxime procedure, is a requisite of the longer procedure before attempting either a gravimetric or volumetric determination of molybdenum.

In connection with the process of removing arsenic and vanadium by precipitating with ammonium hydroxide in the presence of ferric iron, it is to be noted that if lead is present in the original material, and escapes separation as sulphate, it will combine with and retain molybdenum in the precipitate of ferric hydroxide. The amount of molybdenum thus held may be conveniently determined by dissolving the ferric hydroxide in sulphuric acid, treating with potassium thiocyanate and stannous chloride, and comparing the resulting color with that of a standard molybdenum solution by means of a colorimeter.

\section{ACKNOWLEDGMENTS}

The author desires to express his gratitude to G. E. F. Lundell, under whose direction this investigation has been conducted, and also to R. Gilchrist for helpful assistance in the investigation dealing with the platinum metals.

Washington, April 29, 1932. 